\title{
Emergency surgery in older patients
}

\author{
Natalia Dowgiałło-Wnukiewicz, Piotr Kozera, Pawel Lech, Przemysław Rymkiewicz, Maciej Michalik \\ Department of General, Minimally Invasive and Elderly Surgery, University of Warmia and Mazury, Olsztyn, Poland \\ Videosurgery Miniinv 2019; 14 (2): 182-186 \\ DOI: https://doi.org/10.5114/wiitm.2018.77628
}

\begin{abstract}
Introduction: At present, emergency guidelines do not differentiate between younger adults and older persons. The changing socioeconomic situation associated with the aging population will be challenging for the healthcare system and requires new medical guidelines to best accommodate it.

Aim: To analyze whether the age and comorbidities of a patient affect acute care surgical outcomes.

Material and methods: We performed a retrospective study of 161 patients who were admitted in emergency to the Department of General, Minimally Invasive and Elderly Surgery in Olsztyn between May and October 2017. Patients were divided into three age groups. Outcomes in patients older than 80 years were compared with corresponding statistical predictions of morbidity and mortality, as calculated using the Physiologic and Operative Severity Score for the enUmeration of Mortality and Morbidity (POSSUM).

Results: Patients in the 80+ age group had a higher mortality rate in comparison with those in the other age groups, and a higher number of comorbidities ( $p=0.002$ and $p=0.001$, respectively). The POSSUM morbidity and mortality rates were significantly higher for the older patients who died than for the older patients who were discharged ( $p=$ 0.013 and $p=0.003$, respectively).

Conclusions: Decisions about suitable therapy in the acute care setting should be made after consideration of the overall health of a patient. This study shows that age itself has a huge impact on postoperative results. The older the patient is, the higher the risk of perioperative death. We recommend patient evaluation using the POSSUM scale to better predict this risk.
\end{abstract}

Key words: emergency, elderly, Physiologic and Operative Severity Score for the enUmeration of Mortality and Morbidity (POSSUM), older patients.

\section{Introduction}

Technology and improved healthcare in developed countries have extended lifespans to previously unattainable ages. In the European Union the average lifespan is 80.6 years, with 77.9 years for males and 83.3 years for females [1]. These statistics are supported by alarming birth to death ratios of 10.1 and 10.2 per 1000 citizens for males and females, respectively [1]. These two factors prove that the European population is aging rapidly. According to research conducted by Eurostat, this trend will continue in the upcoming decades. It is anticipated that the median age will rise, while the base of the population pyramid will contract. By 2050 , it is estimated that around $30 \%$ of the Polish population will be 65 or older. Data obtained from the Polish National Health Foundation (NFZ) indicate that more than $30 \%$ of hospital admissions in 2016 were for people aged 65 or older [2]. The changing socioeconomic situation associated with the aging population will be challenging for the healthcare system, public finances and medical staff and requires new

\section{Address for correspondence}

Natalia Dowgiałto-Wnukiewicz, Department of General, Minimally Invasive and Elderly Surgery, University of Warmia and Mazury,

2 Michała Oczapowskiego St, 10-719 Olsztyn, Poland, phone: +48 604158 786, e-mail: natalia.dowgiallo@gmail.com 
medical guidelines to best accommodate it. At present emergency guidelines do not differentiate between younger adults, for whom these guidelines were originally developed, and older persons (aged 65 years or above) [3]. However, failure to make this very critical distinction may have serious operative and post-operative consequences that contribute to increased hospitalization times, mortality and morbidity [4-7].

\section{Aim}

The aim of this study was to analyze whether the age and comorbidities of a patient affect acute care surgical outcomes. We evaluated whether it is possible to objectively predict outcomes in older persons according to these parameters. We also examined whether these predictions can be used to determine patient management options, including which patients should undergo surgery with the intention of cure, and which would instead benefit more from minimally invasive treatments or palliative care.

\section{Material and methods}

We performed a retrospective study of 161 patients who were admitted in emergency to the Department of General, Minimally Invasive and Elderly Surgery in Olsztyn between May and October 2017. Patients were divided into three groups: 18-60 years, 61-80 years, and older than 80 years. For each patient, data were gathered during hospitalization, upon relocation to the intensive care unit (ICU) and 3 months after dis- charge. Gender, age, primary diagnosis, comorbidities, length of hospital stay (LOS) and type of discharge were analyzed. Comorbidities were: diabetes mellitus, hypertension, atrial fibrillation, asthma, chronic obstructive pulmonary disease, heart failure, renal failure, hyperthyroidism and hypothyroidism. Emergency surgery outcomes in patients older than 80 years were compared with corresponding statistical predictions of morbidity and mortality, as calculated using the Physiologic and Operative Severity Score for the enUmeration of Mortality and Morbidity (POSSUM) [8].

\section{Statistical analysis}

Statistical analyses were performed using Microsoft Excel 2007 for Windows. Dependence between variables was determined using Qlik Sense software. All data values are presented as the mean and standard deviation. For continuous variables the independent-samples $t$-test was used and a $p$-value below 0.05 was considered as statistically significant.

\section{Results}

The majority of patients were women. Each age group had distinctive characteristics in terms of primary diagnosis and overall response to treatment (Table I).

\section{Age group 18-60}

The most common primary diagnosis in this age group was appendicitis. Of the cases admitted for emergency surgery $1.1 \%$ resulted in death (Table I).

Table I. Characteristic of 161 patients

\begin{tabular}{|c|c|c|c|}
\hline Parameter & $\begin{array}{l}\text { Age group 18-60 } \\
\qquad(n=95)\end{array}$ & $\begin{array}{l}\text { Age group } 61-80 \\
\qquad(n=53)\end{array}$ & $\begin{array}{l}\text { Age group } 80+ \\
\quad(n=13)\end{array}$ \\
\hline Male & $43(45.3 \%)$ & $22(41.5 \%)$ & $5(38.5 \%)$ \\
\hline Female & $52(54.7 \%)$ & 31 (58.5\%) & $8(61.5 \%)$ \\
\hline Predominant primary diagnosis & Appendicitis (56.8\%) & Cholecystitis (26.4\%) & Ileus (38.5\%) \\
\hline $\begin{array}{l}\text { Mean number of comorbidities } \\
\text { per person }\end{array}$ & $0.38 \pm 0.64$ & $1.19 \pm 1.08$ & $2.31 \pm 1.77$ \\
\hline Predominant comorbidity & Hypertension (17.9\%) & Hypertension (62.3\%) & Hypertension (46.2\%) \\
\hline LOS [days] & $3.7 \pm 5.7$ & $5.23 \pm 4.68$ & $7.0 \pm 6.66$ \\
\hline Discharge (\%) & 96.8 & 86.7 & 38.5 \\
\hline ICU (\%) & 2.1 & 5.7 & 7.7 \\
\hline Death (\%) & 1.1 & 7.6 & 53.9 \\
\hline
\end{tabular}




\section{Age group 61-80}

The most common primary diagnosis in this group was cholecystitis. The emergency surgery mortality rate was $9.4 \%$ (Table I).

\section{Age group $80+$}

The majority of patients older than 80 years were admitted to the hospital because of ileus. The average rate of comorbidities was 2.3 per patient. This group had high morbidity and high mortality scores, as predicted by POSSUM, and these scores were supported by a $31 \%$ mortality rate on the surgical ward (Table I). Taking into account patients followed up after relocation to the ICU, the overall mortality rate in this age group was $53.9 \%$. One of the 13 patients was lost to follow-up (Table II).

\section{Comparison between groups}

Patients in the $80+$ age group had a higher mortality rate in comparison with those in the other age groups, and a higher number of comorbidities ( $p=$ 0.002 and $p=0.001$, respectively). There were no statistically significant differences in the LOS between the groups (Table III). The POSSUM predictions of the morbidity and mortality rates were significant higher for the older patients who died than for the older patients who were discharged $(p=0.013$ and $p=0.003$, respectively). There was no significant difference in the number of comorbidities in this comparison (Table IV).

Table II. Characteristic of patients older than 80 years

\begin{tabular}{|c|c|c|c|c|c|c|}
\hline Age & Disease & Procedure & Type of discharge & $\begin{array}{c}\text { Number of } \\
\text { comorbidities }\end{array}$ & $\begin{array}{c}\text { Morbidity } \\
\text { POSSUM } \\
{[\%]}\end{array}$ & $\begin{array}{c}\text { Mortality } \\
\text { POSSUM } \\
{[\%]}\end{array}$ \\
\hline 99 & $\begin{array}{c}\text { Perforation of gastric } \\
\text { ulcer }\end{array}$ & Laparoscopy & Death & 3 & 96.1 & 61.8 \\
\hline 88 & $\begin{array}{l}\text { Ileus - colorectal } \\
\text { cancer }\end{array}$ & $\begin{array}{c}\text { Laparotomy, } \\
\text { left hemicolectomy, } \\
\text { ileostomy }\end{array}$ & Death & 5 & 95.7 & 60.1 \\
\hline 86 & $\begin{array}{l}\text { lleus - unknown } \\
\text { reason }\end{array}$ & Laparoscopy & Discharge & 2 & 37.3 & 6.8 \\
\hline 86 & $\begin{array}{c}\text { Strangulated femoral } \\
\text { hernia }\end{array}$ & Hernioplasty & Discharge & 4 & 59.9 & 13.7 \\
\hline 86 & $\begin{array}{c}\text { lleus - pancreatic } \\
\text { cancer }\end{array}$ & $\begin{array}{c}\text { Laparotomy, tumor } \\
\text { resection, } \\
\text { anastomosis }\end{array}$ & ICU, death & 1 & 96.3 & 63.6 \\
\hline 85 & $\begin{array}{l}\text { Ileus - strangulated } \\
\text { internal hernia }\end{array}$ & $\begin{array}{l}\text { Laparotomy, ileal } \\
\text { resection, } \\
\text { anastomosis }\end{array}$ & Discharge & 5 & 97.8 & 72.5 \\
\hline 85 & $\begin{array}{l}\text { Ileus - colorectal } \\
\text { cancer }\end{array}$ & Laparotomy & ICU, death & 4 & 98.5 & 78.1 \\
\hline 84 & Cholecystitis & $\begin{array}{c}\text { Laparoscopic } \\
\text { cholecystectomy }\end{array}$ & Discharge & 0 & 16.2 & 2.9 \\
\hline 84 & $\begin{array}{l}\text { Ileus - ileostomy } \\
\text { failure }\end{array}$ & Ileostomy repair & Discharge & 0 & 33.6 & 6.1 \\
\hline 82 & $\begin{array}{l}\text { Ileus - colorectal } \\
\text { cancer }\end{array}$ & Laparotomy, bypass & Discharge & 0 & 68.9 & 17.2 \\
\hline 81 & $\begin{array}{l}\text { lleus - unknown } \\
\text { reason }\end{array}$ & $\begin{array}{l}\text { Conventional } \\
\text { treatment }\end{array}$ & ICU, death & 3 & 98.1 & 75.0 \\
\hline 81 & $\begin{array}{l}\text { Gastrointestinal } \\
\text { hemorrhage }\end{array}$ & $\begin{array}{l}\text { Conventional } \\
\text { treatment }\end{array}$ & Death & 1 & 99.7 & 93.7 \\
\hline 81 & $\begin{array}{l}\text { Gastrointestinal } \\
\text { hemorrhage }\end{array}$ & $\begin{array}{l}\text { Conventional } \\
\text { treatment }\end{array}$ & ICU, death & 2 & 98.2 & 79.3 \\
\hline
\end{tabular}




\section{Discussion}

The main reasons why older patients cannot be treated the same as average-aged adults are that they have higher rates of preexisting comorbidities and age-associated mental disorders. Moreover, they often have a reduced will or an overall weakened autonomic response as a result of frailty syndrome [912]. Frailty is a common geriatric syndrome that is characterized by age-associated declines in function across multiorgan systems and leads to increased vulnerability to disease [9-12]. There are numerous studies reporting the influence of frailty syndrome on surgical complications, post-operative outcomes and LOS [4, 12]. Our study found that older patients had longer mean LOS, but the difference was not statistically significant.

Our retrospective study shows that older patients who undergo emergency surgery have significantly higher risk of death in comparison with younger patients. We used the POSSUM scale to predict the risk-adjusted mortality and morbidity rates of the patients included in our study. This scale is used in a wide range of surgical settings and consists of 12 criteria describing the physical state of the patient and 6 criteria concerning the surgery. The physiological parameters include age, cardiac, respiratory and neurological signs and laboratory test results. The surgical parameters include the type of operation, its urgency, and the predicted operative blood loss or peritoneal contamination. The presence of cancer is also taken into account in the calculations [6-8]. All of the patients who died a short time after surgery had mortality rates greater than $95 \%$ and morbidity rates greater than $60 \%$ according to POSSUM. In contrast, the older patients who were discharged from hospital and lived for at least 3 months after the surgery had clearly reduced mortality and morbidity rates. Therefore, POSSUM appears to be a useful tool for predicting severe complications of surgery in older persons. This conclusion is supported by the findings of other studies in the published literature [6-8].

Using a scale that incorporates the patient's physical state within the calculated risk may help the surgeon to most appropriately manage a patient. Operative decisions should be made taking into account the overall state of the patient, including their general condition, age and consent [10, 12-15]. It is important that the potential benefits of the surgery outweigh the risks of complications.
Table III. Comparison between age groups regarding mortality rate, comorbidities and LOS

\begin{tabular}{|lccc|}
\hline Parameter & \multicolumn{2}{c}{ Age groups } & P-value \\
\cline { 2 - 3 } & $18-80$ & $80+$ & \\
\hline Mortality rate $(\%)$ & $0.03 \pm 0.18$ & $0.54 \pm 0.5$ & 0.002 \\
\hline Comorbidities $[n]$ & $0.28 \pm 0.56$ & $2.31 \pm 1.77$ & 0.001 \\
\hline LOS [days] & $3.97 \pm 5.5$ & $7.0 \pm 6.66$ & NS \\
\hline
\end{tabular}

Table IV. Comparison between died and discharged patients older than 80 years

\begin{tabular}{|lccc|}
\hline Parameter & Death & Discharge & $P$-value \\
\hline $\begin{array}{l}\text { Morbidity } \\
\text { POSSUM (\%) }\end{array}$ & $97.51 \pm 1.38$ & $52.28 \pm 26.71$ & 0.013 \\
\hline $\begin{array}{l}\text { Mortality } \\
\text { POSSUM (\%) }\end{array}$ & $73.09 \pm 11.2$ & $19.87 \pm 24.06$ & 0.003 \\
\hline $\begin{array}{l}\text { Comorbidities } \\
\text { [days] }\end{array}$ & $2.71 \pm 1.39$ & $1.83 \pm 2.03$ & NS \\
\hline
\end{tabular}

In cases involving high-risk patients, treatments that are minimally invasive should be selected to avoid overzealous treatment. Overzealous therapy is the use of medical procedures that prolong dying and cause excessive suffering $[16,17]$. Older patients who are in a poor initial condition should receive care that maintains their dignity, such as good nursing, control of pain and other symptoms and feeding and fluid administration. These types of care should be provided as long as they are beneficial to the dying person. Surgical management of cases such as these may be futile and burdensome therapy.

Depending on the case, minimally invasive procedures such as laparoscopy should be considered instead of open procedures such as laparotomy, and withholding surgery completely should also be considered $[10,15]$. Less traumatic procedures that have lower risks of complications than normal surgery should also be favored. For example, endoscopic or invasive ultrasound therapy should be performed as required to address bleeding or a pseudocyst, or to allow stent placement to relieve an obstruction of the gastrointestinal tract $[18,19]$.

Limitations of our analysis include the small sample size of patients and the heterogeneity of the age groups. Nevertheless, our results are similar to those reported in other studies. Further investigation in- 
volving larger sample sizes should be performed in future.

\section{Conclusions}

At present, there are no surgical guidelines that are specific for older persons. Decisions about suitable therapy in the acute care setting should be made after consideration of the overall health of a patient. This study shows that age itself has a huge impact on postoperative results. The older the patient is, the higher the risk of perioperative death. We recommend patient evaluation using the POSSUM scale to better predict this risk. Patients with higher mortality and morbidity scores should be very carefully selected for surgery. For cases in which the risk of postoperative complications are greater than the potential benefits of the treatment, minimally invasive or even palliative treatment should be considered instead.

\section{Acknowledgments}

We thank Shelley Robison, PhD, from Edanz Group (www.edanzediting.com/ac) for editing a draft of this manuscript.

\section{Conflict of interest}

The authors declare no conflict of interest.

\section{References}

1. Official Eurostat statistics. www.ec.europa.eu/eurostat/statistics-explained/index.php/File:Life_expectancy_at_birth,_19802015_(years).png February 2018.

2. Official Polish National Health Foundation statistics. February 2018 https://prog.nfz.gov.pl/app-jgp/AnalizaPrzekrojowa.aspx (Access on February 15.2018).

3. St-Louis E, Sudarshan M, Al-Habboubi M, et al. The outcomes of the elderly in acute care general surgery. Eur J Trauma Emerg Surg 2016; 42: 107-13.

4. Søreide K, Desserud KF. Emergency surgery in the elderly: the balance between function, frailty, fatality and futility. Scand J Trauma Resusc Emerg Med 2015; 23: 10.

5. Davis P, Hayden J, Springer J, et al. Prognostic factors for morbidity and mortality in elderly patients undergoing acute gastrointestinal surgery: a systematic review. Can J Surg 2014; 57: 44-52.

6. Ambarish S, Chatterjee DN, Renganathan. POSSUM: a scoring system for perforative peritonitis. J Clin Diagn Res 2015; 9: PC05-09.

7. Sharrock A, McLachlan J, Chambers R, et al. Emergency abdominal surgery in the elderly: can we predict mortality? World J Surg 2017; 41: 402-9.
8. Scott S, Lund JN, Gold S, et al. An evaluation of POSSUM and P-POSSUM scoring in predicting post-operative mortality in a level 1 critical care setting. BMC Anesthesiol 2014; 14: 104.

9. Jui-Ying C, Wan-Yu C, Ta-Wei L, et al. An analysis of surgical outcomes in patients aged 80 years and older. Acta Anaesthesiol Taiwan 2014; 52: 153-8.

10. Michalik M, Dowgiałło-Wnukiewicz N, Lech P, et al. Surgery of the elderly in emergency room mode. Is there a place for laparoscopy? Videosurgery Miniinv 2017; 12: 115-9.

11. Chen X, Mao G, Leng SX. Frailty syndrome: an overview. Clin Interv Aging 2014; 9: 433-41.

12. Rockwood K, Song X, MacKnight C, et al. A global clinical measure of fitness and frailty in elderly people. CMAJ 2005; 173: 489-95.

13. Lin HS, Watts JN, Peel NM, et al. Frailty and post-operative outcomes in older surgical patients: a systematic review. BMC Geriatr 2016; 16: 157.

14. Torrance ADW, Powell SL, Griffiths EA. Emergency surgery in the elderly: challenges and solutions. OAEM 2015; 7: 55-68.

15. Wilson I, Paul Barrett M, Sinha A, et al. Predictors of in-hospital mortality amongst octogenarians undergoing emergency general surgery: a retrospective cohort study. Int I Surg 2014; 12: 1157-61.

16. Bock JO, König HH, Brenner $\mathrm{H}$, et al. Associations of frailty with health care costs - results of the ESTHER cohort study. BMC Health Serv Res 2016; 16: 128.

17. Maffei S, Colantoni A, Kaleci S, et al. Clinical features of colorectal cancer patients in advanced age: a population-based approach. Intern Emerg Med 2016; 11: 191-7.

18. Skorus UA, Kenig J. Outcome of esophageal cancer in the elderly - systematic review of the literature. Videosurgery Miniinv 2017; 12: 341-9.

19. Szeliga J, Jackowski M. Minimally invasive procedures in severe acute pancreatitis treatment - assessment of benefits and possibilities of use. Videosurgery Miniinv 2014; 9: 170-8.

Received: 15.05.2018, accepted: 13.07.2018. 